\title{
International survey of the utilisation of physiotherapy in treatment centers for survivors of torture
}

\author{
Laura Pizer Gueron, LPG' and MaryAnn de Ruiter, MR ${ }^{2}$
}

\section{Key points of interest}

- Survivors of torture at nearly $1 / 3$ of responding treatment centers do not have access to physiotherapy, either on-site or externally

- Lack of funds/resources and shortage of physiotherapy personnel were perceived as being the biggest challenges limiting access by clients to physiotherapy

\begin{abstract}
Introduction: Literature about treatment of survivors of torture tends to focus on counseling and primary medical care. There are fewer articles about the utilisation of physiotherapy (PS) at treatment centers for survivors of torture and other forms of trauma.
\end{abstract}

1) Clinical Advisor for Physiotherapy, Kenya Programs, Center for Victims of Torture. Correspondence to: lgueron@cvt.org or lgueron@gillettechildrens.com

2) Former Clinical Advisor for Physiotherapy, Jordan Programs, Center for Victims of Torture. Physiotherapist with Minneapolis Public Schools. Correspondence to: maryann.deruiter@mpls.k12. mn.us
Methods: A survey about utilisation of PS at treatment centers for survivors $(n=87)$.

Results: Approximately $30 \%$ of centers report that their patients have no access to PS, one third having physiotherapy on staff. One third of responding torture treatment programs reported being able to refer to physiotherapists (PT) outside of their centers. Therapeutic exercise, manual therapy, massage, group activities and exercises were the most commonly reported treatment modalities provided by PT. Lack of funds or resources and shortage of physiotherapy personnel were perceived as being the biggest challenges limiting patients' access to PS. Twenty-nine of the respondents (33\%) were PT, and of these, 90\% reported being interested in collaborative activities with other PT working with survivor of torture.

Keywords: Physiotherapy, international survey, modalities, barriers, collaboration.

\section{Introduction}

There are more than 200 treatment centers for survivors of torture (SoT) in the world. (International Rehabilitation Council for Torture Victims (IRCT) ${ }^{1}, 2020$; National Capacity Building Project (NCB) ${ }^{2}$, 2020; United Nations Voluntary Fund for Victims of Torture (UNVF), 2020). There is a wide range of care providers at these centers, with some providing extensive interdisciplinary 
services and some with a more limited focus. Many programs for SoT have a strong mental health focus (Bunn et al., 2016; Kira et al., 2012) while some have an interdisciplinary approach that combines counseling and PS (Amris et al., 2019; Baird et al., 2017; Harlacher et al., 2019; Nordbrandt et al., 2020; Stammel et al., 2017; Wang et al., 2016).

\section{Methods}

In 2014, a list of treatment centers around the world was compiled by combining lists of centers for survivors from the IRCT, NCB in the United States and UNVF. Six doctoral PS students from the University of Minnesota helped to create an online survey which asked targeted questions of treatment center staff members and translated the survey from English into Spanish and French. The cover letter that was emailed made the request to forward the survey to a staff PT if there was any working at the center. If there were not PT working at that site, any staff member could fill it out. There were targeted questions for PT only at the end of the survey.

If an email was "automatically returned to the sender," a second survey was sent to additional email addresses at the same center if possible. A second survey was also re-sent where emails had not been rejected, but where the recipient had not responded.

Figure 1. Sampling process for international survey

List compiled of all recipients of funding from United Nations Voluntary

Fund $(\mathrm{n}=169)$, IRCT members $(\mathrm{n}=150)$ and National Capacity Building members $(n=40)$ Total 359

\begin{tabular}{|c|}
\hline Eliminated duplicate centers by comparing the three lists \\
$\mathrm{n}=250$ remaining
\end{tabular}


PT were asked the same questions as non-PT, plus additional questions about their educational level and years of experience. Data is analyzed separately for the questions about biggest perceived problems in providing PS and interest in collaborating with other professionals working with SoT.

Eighty- seven surveys were completed. The response rate was $43 \%$ out of 200 emails sent.

\section{Results}

Of the 87 respondents, 42 were from the Global North and 45 from the Global South. Fourteen were working at centers in the USA, six from Cambodia, five from Denmark, four from Italy, and three each from Bosnia and Herzegovina, India, and Lebanon. There were two respondents each from Australia, Democratic Republic of Congo, Finland, Germany, Indonesia, Jordan, Kenya, Liberia, Palestine, Rwanda, Sri Lanka, Sweden, Turkey and the United Kingdom. Finally, there was one respondent each from Armenia, Austria, Belgium, Bulgaria, Burundi, Chad, Chile, Ecuador, Egypt, France, Honduras, Ireland, Israel, Kyrgyzstan, Morocco, Nepal, New Zealand, Nigeria, Norway, Romania, and Serbia.

There were no large differences between the Global North and Global South in the percentages of centers offering PS either onsite or by external referral, except that in all responding centers in South and Central Asia, patients had access to PS, as indicated in Figure 2 below.
Figure 2. Percentages of centers where patients have no access to PS, across regions

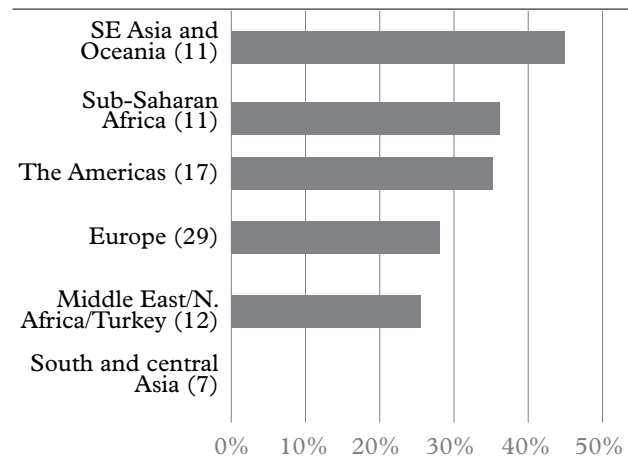

At the treatment centers for SoT, psychotherapy/counseling was available at $85 \%$ of the centers, followed by social work (73\%), psychiatry $(63 \%)$, and primary medicine $(55 \%)$. PT were on staff at $33 \%$ of the centers, massage therapists at $27 \%$, and nursing and occupational therapists at $25 \%$.

Figure 3. Professionals working at centers for SoT

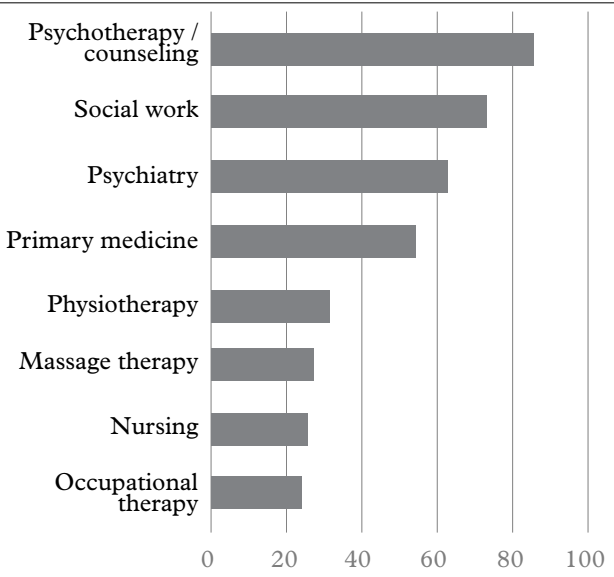

PT working at treatment centers for SoT who answered the survey tended to be both highly educated and experienced with $82 \%$ 
holding at least a baccalaureate bachelor degree, $86 \%$ percent with at least 5 years of experience, and $59 \%$ having eleven or more years of experience as a PT. Additionally, $55 \%$ of PT respondents have at least 6 years of experience specialising in torture and trauma rehabilitation.

Figure 4. Educational level of PT at centers with PT on staff

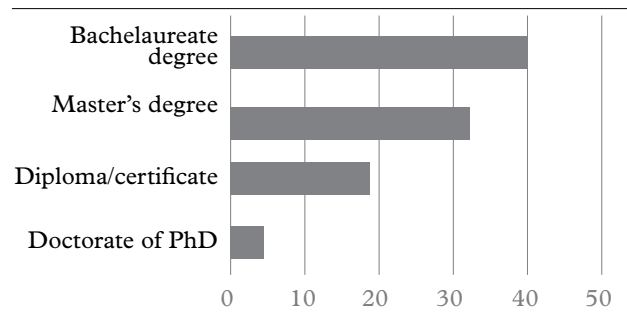

While at $30 \%$ of the centers, the patients have no access to PS services, at $22 \%$ of centers the patients can receive PS offsite, $20 \%$ onsite at the center only and at $29 \%$ of the centers, the patients can receive PS either at their center for SoT or be referred externally for PS services. At the centers where there is a PT on staff, unsurprisingly, the percentage of patients receiving PS services is increased.

Figure 5. Patient's access to PS services

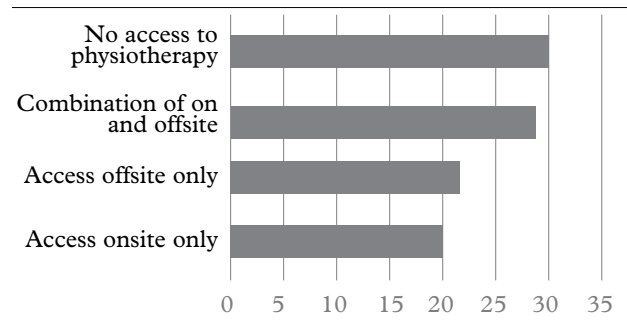

In the one third of centers where there is a PT on staff, a higher percentage of patients received PS than those where there is not a PT staff. (See full survey report in supplemental material).
Figure 6. Percentage of patients receiving PS when there are PS services onsite

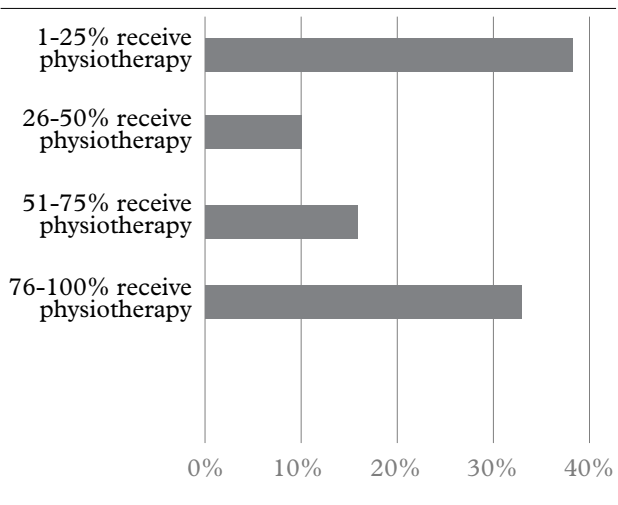

Figure 7. Percentage of patients receiving PS when there is no PT onsite

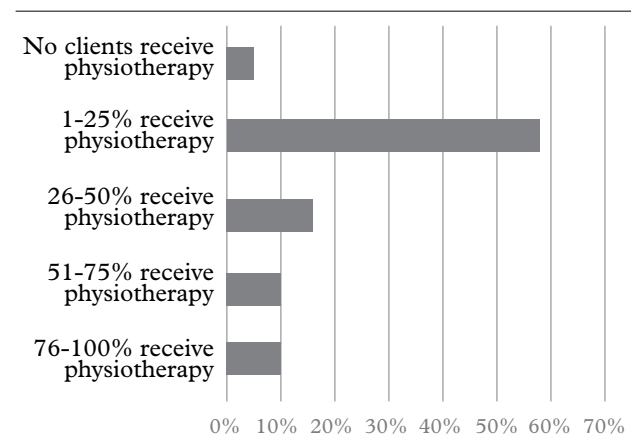

PT were asked to check all modalities which they used with patients. The most frequently were therapeutic exercise for individuals $(85 \%)$, manual therapy $(75 \%)$, massage $(70 \%)$ or group exercises/activities $(65 \%)$. The least common were aquatic exercise $(15 \%)$, home evaluations (35\%), taping $(40 \%)$, or provision of durable medical equipment such as wheelchairs, crutches, walkers (40\%). U1trasound and electrical stimulation treatments were also used by 35 and $40 \%$ of PT respectively. There were additional treatments mentioned, including dry needing, body awareness training, the Feldenkrais method, graded 
motor imagery, dry heat therapy and laser therapy.

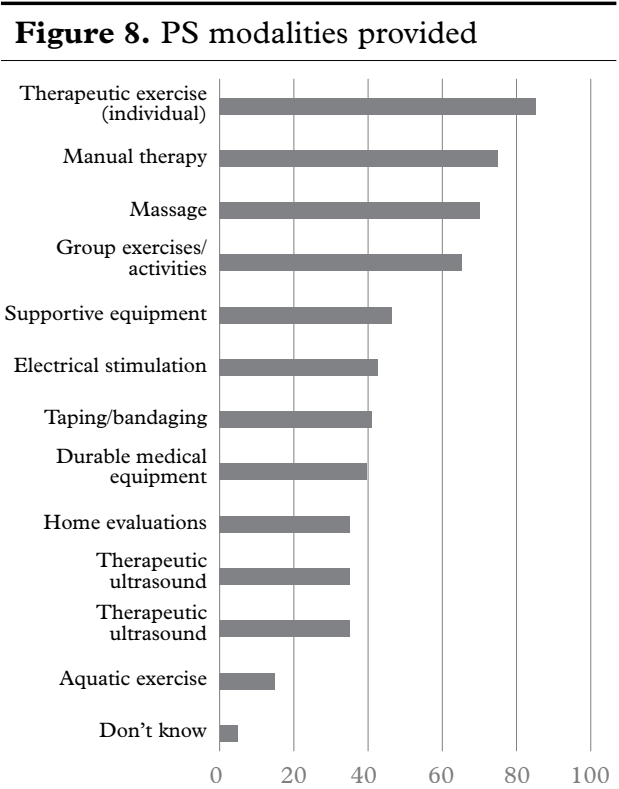

Both PT and non-PT indicated lack of funds/resources and lack of personnel as being among the main challenges and limitations to providing PS services to survivors. Twenty-two respondents working at centers with no PT present decried the lack of funds as a perceived limitation. PT indicated that lack of time with patients and systemic barriers were the greatest challenges.
Figure 9. Perceived limitations to providing PS at treatment centers where there is no PT onsite (answered by non-PT)

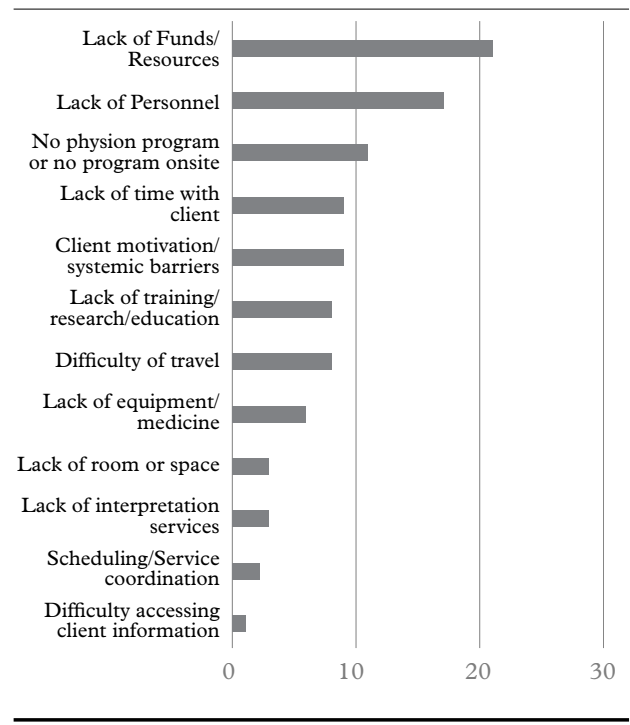

Figure 10. Perceived limitations to providing adequate PS services at treatment centers where there are PT onsite-perceptions of the PTs themselves

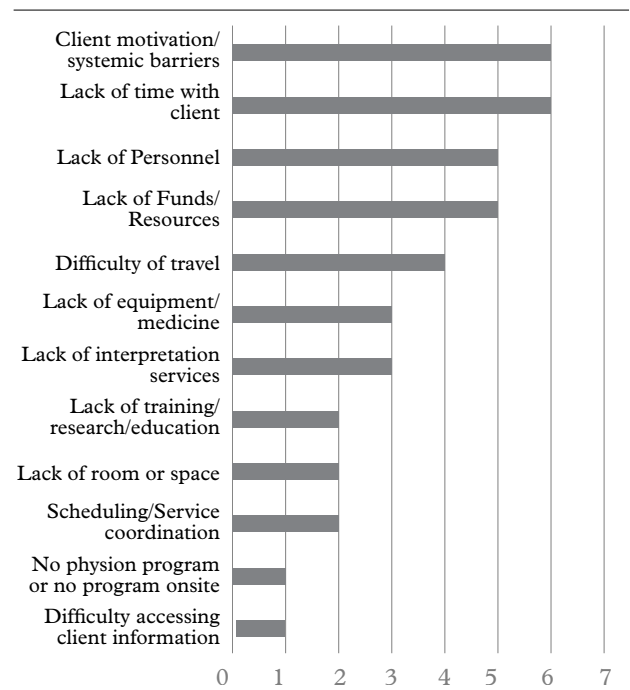


Ninety percent of the PT surveyed expressed interest in participating in collaborative activities with other PT who work with SoT. One third were interested in participating in a Facebook group, one third in attending webinars about PS treatment for SoT, $19 \%$ in being part of a listserv and $21 \%$ in organizing on LinkedIn.

Once the survey results were analysed, all participants were sent a copy of the survey report. In addition, based on the PT expressed interest, in 2016, a Facebook group was created for PT who are interested in working with SoT. The group now has 224 members from 36 countries. While the group is mostly comprised of PT, there are several occupational therapists, massage therapists, chiropractors and medical doctors who are members. There are also PS students from several countries who participate in the group, which has become a forum for sharing resources for those working with refugees and for those who are interested in mind-body approaches for the healing of trauma. Anyone interested in being vetted to join the Facebook group for PTs working with SoT and other forms of trauma can correspond with either of the authors to get more information. In addition, a PS section on the HealTorture.org website was created in response to interests expressed on the international survey. There are links to webinars, PS article reviews and blogs about physiotherapy for SoT. ${ }^{1}$

\section{References:}

Amris, K., Jones, L., \& Williams, A. (2019). Pain from torture: Assessment and management. Pain Reports, 4(6), e 794. https://doi.org/10.1097/ PR9.0000000000000794

Baird, E., de Williams, C., Hearn, A., \& Amris, K. (2017) Interventions for treating persistent pain in survivors of torture. Cochrane Database Systems Review. https://doi.org/10.1002/14651858.

1 https://healtorture.org/content/physicaltherapyphysiotherapy

CD012051

Bunn, M., Goesel, C., Kinet, M., \& Ray, F. (2016). Group treatment for survivors of torture and severe violence: A literature review. Torture, 26(1), 45-67. https://doi.org/10.7146/torture. v26i1.108062

Gamble, A, Ahmed, A. M. A., Rahim, S. H., \& Hartman, J. (2020). The effects of combined psychotherapy and physiotherapy group treatment program for survivors of torture incarcerated in an adult prison in Kurdistan, Iraq: A pilot study. Torture, 30(2), 58-76. https:// doi.org/10.7146/torture.v30i2.119199

Gueron, L. P., Amoyi, A., Chao, W., Chepngetcih, J., Kibet, J. J., Nyambok, S., \& Wesonga, J. (2020). Group physiotherapy with survivors in urban and camp settings in Jordan and Kenya. Torture, $30(2)$, this issue.

Harlacher, U., Polatin, P., Taing, S., Phana, P., Sok., P., \& Sothera, C. (2019). Education as a treatment for chronic pain in survivors of trauma in Cambodia: Results of a randomized controlled outcome trial. International fournal of Conflict and Violence, 13, 1-26. https://doi:10.4119/UNI9/ijcv.655

Kira, I.A., Ahmed, A., Mahmoud, V., \& Wassim, E. (2010). Group therapy model for refugee and torture survivors: Treatment model innovations. International fournal of Group Psychotherapy, 62(1). https://doi.org/10.1521/ijgp.2012.62.1.69

Nordbrandt, M. S., Sonne, C., Mortensen, E. L., \& Carlsson, J. (2020). Trauma-affected refugees treated with basic body awareness therapy or mixed physical activity as augmentation to treatment as usual-A pragmatic randomized controlled trial. PLos One, 15(3), e0230300. https://doi.org/10.1371/journal.pone.0230300

Stammel, S., Knaevelsud, C., Schock, K., Walther, L.C. S., Wenk-Ansohm, M. P., \& Bottche, M. (2017). Multidisciplinary treatment for traumatized refugees in a naturalistic setting: symptom courses and predictors. European fournal of Psychotraumatology. 8(2), https://doi.org /10.1080/20008198.2017.1377552

Wang, S., Bytyci, A., Izeti, S., Hallaba, M., Rushti, R., Montgomery, E., \& Modvig, J. (2016). A novel bio-psycho-social approach for rehabilitation of traumatized victims of torture and war in the postconflict context: A pilot randomized controlled trial in Kosovo. Conflict and Health, 10(34). https:// doi.org/10.1186/s1303'-016-0100-y

Yuce, H., \& Bahrilli, T. (2020). The impact of Basic Body Awareness Therapy on balance and quality of life in survivors of hunger strike with Wernicke Korsakoff syndrome. Torture, 30(2), 77-88. https://doi.org/10.7146/torture.v30i2.120163 


\section{Acknowledgements}

Thanks to the many doctoral physiotherapy students at the University of Minnesota, who volunteer helping the Center of Victims of Torture (CVT) physiotherapy team with special projects such as this survey. Thanks to Ann Lundberg from the National Capacity Building Project and Anna Zaros, for helping in creating and analysing the survey and to Craig Higson-Smith, for reviewing. 